\title{
PASTÖRİZE LİKİT YUMURTA ÜRETİM PLANI OPTIMIIZASYONU
}

\author{
Murat KOCAMAZ*, Ural Gökay ÇiçEKLí** \\ ÖZET
}

Üretim planlama; hammadde, ürün ve makine kısıtları arasındaki ilişkiler karmaşıklaşıı̆ında zor bir optimizasyon problemi haline gelmektedir. Çalışma kapsamında, belirli üretim kısıtları altında likit yumurta üretim planı optimize edilmektedir. Problemin çözümünde, uygulamada karşılaşılan kısıtların göz önüne alındığı "Genelleştirilmiş İndirgenmiş Gradyenler" temelli bir üretim planı modeli geliştirilmiştir. Geliştirilen model kapsamında ortaya çıkan üretim planı, ürün karmasının yapısını ve makinelerdeki yumurta kırım planlarını içermektedir. Kapasite, kıım oranı, briks değeri, makine kullanım oranı, SIVı oranı ve intiyaç duyulan ürün kısıtları altında toplam üretim miktarının maksimize edilmesi hedefi doğrultusunda elde edilen sonuçlar çalışmada verilmektedir.

Anahtar Sözcükler: Optimizasyon, Doğrusal Olmayan Programlama, Üretim Planlama, Genelleştirilmiş İndirgenmiş Gradyenler

\section{OPTIMIZATION FOR PRODUCTION PLANNING OF LIQUID EGG}

\begin{abstract}
Production planning becomes a difficult optimisation problem when the relationship between material, product and machine constraints is complicated. In this study, liquid egg production plan was optimized under specific production constraints. As a solution to the problem, a "Generalized Reduced Gradient"-based production planning model is developed, which considers the constraints encountered in real-life practice. The results yielded in the study in accordance with the objective of maximizing the total production under the constraints of capacity, breaking ratio, brix value, machine utilization ratio, liquid ratio and required product, are presented.
\end{abstract}

Keywords: Optimization, Nonlinear Programming, Production Planning, Generalized Reduced Gradient

\footnotetext{
*Ege Üniversitesi, İİBF, İşletme Bölümü, Bornova, İzmir, E-posta: murat.kocamaz@ege.edu.tr

${ }^{* *}$ Ege Üniversitesi, İ̇̈BF, İşletme Bölümü, Bornova, İzmir, E-posta: gokay.cicekli@ege.edu.tr
} 


\section{GİRISS}

Problemler sahip oldukları amaç fonksiyonları ve kısıtlarına göre doğrusal veya doğrusal olmayan fonksiyonlar ile ifade edilmektedir. Problemlerin fonksiyon yapılarına göre programlama modeline karar verilmektedir. Doğrusal programlama, karar verici doğrusal bir amaç fonksiyonu kurarak, doğrusal kısıtlar altında modeli optimize etmeyi hedeflemektedir (Ulucan, 2004: 245). Fakat gerçek hayat problemleri, sürekli değişkenlere sahip doğrusal yapı göstermemektedir (Rardin, 1998: 131). Doğrusal yapıya sahip olmayan bu tür problemlerde doğrusal olmayan programlama modelleri kullanılmaktadır. Doğrusal olmayan programlama problemleri, optimizasyon yaklaşımı gerektiren mühendislik, karar verme ve sanayi uygulamalarında sıklıkla kullanılmaktadır.

Üretim süreçleri girdi ve çıktı arasındaki ilişkiye göre analitik ve sentetik olmak üzere ikiye ayrılmaktadır. Analitik sistem hammaddeleri ayrıştırarak yeni ürünler elde ederken, sentetik sistem ise hammaddelerin birleşiminden tek ürün elde etmektedir (Boone ve Kurtz, 2010: 359). Likit yumurta (liquid egg product - LEP); yumurtanın kabuğundan ayırılarak, bütün yumurta, ayrışmış sarı, ayrışmış ak ya da belirli bir karışım şeklinde pazarlanmasıdır (Prochaska, Carey ve Shafer, 1996: 1268). Likit yumurta üretim sürecinde de kabuklu yumurta tek girdi olarak kullanılıp farklı ürünler elde edilmektedir. Analitik yapı gösteren bu tip üretim, elde edilecek ürünlerin özelliklerine uygun karışımların yapılmasını gerektirmektedir. Makine kısıtları, kırım oranları, girdi kısıtları ve üretim hedefleri göz önünde bulundurulduğunda doğrusal olmayan bir yapıya sahip olan likit yumurta üretim planı optimizasyonu oldukça zor hale gelmektedir.

Bu çalışmanın amacı kısıtlar dahilinde likit yumurta üretim planını optimize etmektir. Geliştirilen model kapsamında ortaya çıkan üretim planı, ürün karmasının yapısını ve makinelerdeki yumurta kırım planlarını içermektedir.

\section{OPTİMİZASYON ALGORİTMASI}

Optimizasyon, problemdeki faydaları maksimize etmek ve kayıpları azaltmak amacıyla, farklı alternatifler arasından en iyi sonucu seçme sanatıdır (Fahim ve Helmy, 2012: 1). Bu çalışmada, doğrusal olmayan programlama yapısına sahip likit yumurta üretim planlaması optimizasyonu için genelleştirilmiş indirgenmiş gradyenler (Generalized Reduced Gradient - GRG) yöntemi kullanıımıştır. 


\section{Pastörize Likit Yumurta Üretim Planı Optimizasyonu}

GRG algoritmasının, uygulama açısından, tekrarlamalı doğrusallaştırma kullanan genel algoritmalar içerisinde en iyilerinden biri olduğu bilinmektedir (Su ve Lii, 1995: 181). Bazı karşılaştırmalı çalışmalara göre, GRG yöntemi en iyi deterministik yerel optimizasyon yöntemlerinden biridir (Kao, 1998: 807). Kısıtların yer aldığı uygulanabilir optimizasyon yöntemlerinden birisi olan GRG, teknolojik uygulamalarda yaygın olarak kullanılmakta ve önemli bir rol oynamaktadır (Mouatasim, 2010: 2).

GRG algoritması fikri ilk olarak kısıtı türev kavramının formüle edilmesiyle ortaya çıkmış ve geliştirilerek indirgenmiş gradyen yöntemi adıyla kullanılmaya başlanmıştır (Sharma ve Glemmestad, 2013: 1134). Problem boyutlarını azaltmayı amaçlayan indirgenmiş gradyen yöntemi, doğrusal kısıtlı doğrusal olmayan programlama problemini çözebilmek amacıyla Wolfe (1963) tarafından geliştirilmiştir. Abadie ve Carpentier doğrusal olmayan kısıtları ele almak üzere GRG yöntemini genelleştirmişlerdir (Bazaraa, Sherali ve Shetty, 2006: 602).

GRG yöntemi, eşitlik kısıtları kullanarak değişkenlerin ortadan kaldırımasını amaçlamaktadır (Yeniay, 2005: 167). GRG yönteminin çözüm yaklaşımı, tüm kısıtları karşılarken amaç fonksiyonu içinde daha iyi bir yön bulma amacı taşımaktadır (Faluyi ve Arum, 2012: 305).

Basit indirgeme gerektiren Armijo satır aramalar (Lee, Chen ve Kang, 2004: 27; Sun ve Yuan, 2006: 509) kullanan GRG, optimizasyon yöntemlerini doğrusal durumdan doğrusal olmayan duruma genişletmeye çalışmaktadır (Mouatasim, 2010: 5). GRG algoritması aşağıdaki gibi özetlenebilir (Edgar ve Himmelblau, 1989; Su ve Lii, 1995):

Adım 1: $X_{I}$ bağımsız değişkenlerin vektörü ve $X_{D}$ bağımlı değişkenlerin vektörü olarak tanımlanmaktadır. Aşama $k$ da, mümkün olan $X^{k}$ noktasındaki kısıtlamalar doğrusallaştırıır ve indirgenmiş gradyeni hesaplanır.

$$
\left(g_{R}^{k}\right)^{T}=\left[\frac{\partial f^{k}}{\partial X_{I}^{k}}\right]^{T}-\left[\frac{\partial f^{k}}{\partial X_{D}^{k}}\right]^{T}\left[\frac{\partial h^{k}}{\partial X_{D}^{k}}\right]^{-1}\left[\frac{\partial h^{k}}{\partial X_{I}^{k}}\right]
$$

Adım 2: Bağımsız değişkenler için arama bileşenleri belirlenir.

Adım 3: Bağımlı değişkenler için arama bileşenleri belirlenir.

Adım 4: Amaç fonksiyonu değeri geliştirilir.

Adım 5: Bağımlı değişkenleri olanaklı hale getirmek için Newton yöntemi kullanılır.

Adım 6: Süreç, $\varepsilon_{i \mathfrak{i}}$ büyüklüğü xi ölçeğine bağlı olan küçük bir sayı olduğu yerde $\left|\Delta_{i}^{k}\right|<\varepsilon_{i \mathfrak{i}}, i=1_{s, n}, n$, koşulunun sağlanıp sağlanmadığını 


\section{Murat Kocamaz ve Ural Gökay Çiçekli}

kontrol ederek adım 4 'ten sonra sonlanır. Son olarak $X_{D}$ ve $X_{V}$ 'den uygun $x^{*}$ sonucu elde edilir.

\section{PROBLEMİN TANIMLANMASI}

Likit yumurta üretimi yapılan bir firmada gerçekleştirilen optimizasyon çalışmasında, iki farklı tip makinede kırıımı yapılan yumurtalardan yumurta bütünü, yumurta sarısı, yumurta akı ve yumurta melanjı olmak üzere 4 farklı yarı mamul elde edilmektedir. Bu yarı mamuller farklı oranlarda karıştııılıktan sonra pastörize edilerek ürünlere dönüştürülmektedir. Elde edilen 4 farklı üründen, yumurta bütünü, yumurta akı ve yumurta sarısı kutular halinde, endüstriyel yumurta bütünü ise 1 tonluk tanklarda satılmaktadır. Endüstriyel yumurta bütünü müşterinin isteğine göre farklı briks değerlerinde üretilebilirken kutulu ürünlerin briks oranları değişmemektedir. Çalışma kapsamında ele alınan problemde; kapasite, kırım oranı, briks değeri, makine kullanım oranı, sıvı oranı ve ihtiyaç duyulan ürün kısıtları doğrultusunda toplam likit yumurta üretim miktarının maksimize edilmesi amaçlanmaktadır.

\section{Problemin Kısıtları}

Makine kapasite kısıtı. Üretim tesisinde bulunan 2 makine, kırım kapasiteleri ve kırım kabiliyetleri açısından farklılık göstermektedir. Makine 1 yumurtayı sadece bütün olarak kırabilmekte, makine 2 ise yumurtayı bütün veya istendiğinde sarısı ve akı olarak ayırabilmektedir. Bu koşullar altında günlük makine kırım kapasitelerini $\left(C d_{m i}\right)$ kilogram $(\mathrm{kg})$ cinsinden hesaplamak için her iki makineye ait günlük çalışma saatleri $\left(H_{m i}\right), \mathrm{kg}$ verimlilikleri $\left(E_{m i}\right)$ ve $\mathrm{kg}$ cinsinden saatte kırabilecekleri maksimum yumurta ağırlıkları $\left(C h_{m i}\right)$ gerekmektedir. Makine 2 için yumurtanın bütün kırılması veya ayrıştırılarak kırılmasında herhangi bir kapasite değişikliği yaşanmamaktadır.

\section{Tablo 1: Makine Kapasite Kısıtları}

\begin{tabular}{lll} 
& Makine 1 & Makine 2 \\
\hline Günlük Çalışma Saati & $H_{m 1}$ & $H_{m 2}$ \\
\hline Verimlilik & $E_{m 1}$ & $E_{m 2}$ \\
\hline Saatlik Kırma Kapasitesi & $C h_{m 1}$ & $C h_{m 2}$ \\
\hline
\end{tabular}

Makinelerin günlük kapasite kısıtı;

$$
C d_{m i}=H_{m i} * E_{m i} * C h_{m i}
$$




\section{Pastörize Likit Yumurta Üretim Planı Optimizasyonu}

Yumurta kırım oranları. Yumurtalar makine 2 tarafından bütün olarak kırımak yerine ayrıştırıldığında ortaya sadece yumurta sarısı ve akı çıkmamaktadır. Ayrışıırma sürecinden kaynaklanan kalite kaybı ile toplam yumurta ağırlığının bir kısmı yumurta sarısı (ey) ve akının (ew) karışık olarak geldiği melanj ürün $(\mathrm{em})$ olarak ayrıştırılmaktadır. Bu oranlar yalnızca makine 2'de oluşmakta, makine 1'de yumurta akı, sarısı ve melanjı ayrıştırılamamaktadır.

\section{Tablo 2: Yumurta Kırım Oranları}

\begin{tabular}{ll} 
& Oran \\
\hline Yumurta Sarısı Oranı & $R_{\text {ey }}$ \\
\hline Yumurta Akı Oranı & $R_{\text {ew }}$ \\
\hline Yumurta Melanjı Oranı & $R_{\text {em }}$ \\
\hline
\end{tabular}

Briks kısıtı. Kuru maddeler, suda çözünür kuru madde ve çözünmeyen kuru madde olmak üzere ikiye ayrılmaktadır. Büyük moleküllü maddeler suda çözünmeyen, küçük moleküllü bazı maddeler ve bazı vitaminler ise suda çözünen kuru maddelerdir. Alman Matematikçi Adolf Ferdinand Wenceslaus Brix sakaroz oranları hakkında çalışırken yaptığı geliştirmeler ile suda çözünen kuru madde oranına Briks ismini vermiştir (Kimball, 1991: 8). Pastörize yumurta üretiminde, gerek ürünlerin gerekse girdilerin briks değerleri ürün kalitesini ve özelliğini belirleyen temel değerlerden biridir. Ürünlere ait briks değerlerinin $(B r)$ alabilecekleri alt $\left(B r_{\min }\right)$ ve üst $\left(B r_{\max }\right)$ oranlar, endüstriyel yumurta bütünü $(i e)$, yumurta bütünü $(e)$ ve yumurta sarısı (ey) için değişiklik göstermektedir.

\section{Tablo 3: Girdi ve Ürün Briks Değerleri}

\begin{tabular}{|c|c|c|}
\hline \multicolumn{3}{|l|}{ Girdiler } \\
\hline \multicolumn{3}{|c|}{$x_{\mathrm{i}}$ değişkenleri için briks değeri $=B r_{\mathfrak{i}}\left(i=1_{x \ldots n} n\right)$} \\
\hline Ürünler & $B r_{\min }$ & $B r_{\max }$ \\
\hline Endüstriyel Yumurta Bütünü & $B r_{\text {minie }}$ & $B r_{\text {maxie }}$ \\
\hline Yumurta Bütünü & $B r_{\min e}$ & $B r_{\max e}$ \\
\hline Yumurta Sarısı & $B r_{\text {miney }}$ & $B r_{\max }$ \\
\hline
\end{tabular}

Makine 1 girdisi kısıtları. Ürünlerin içinde yer alan yumurtaların makine $1^{\prime}$ den gelme oranı alt $\left(M 1_{\min }\right)$ ve üst $\left(M 2_{\max }\right)$ değerlerle sınırlanmaktadır. Gerek maliyet gerekse kalite arttırma hedefiyle yapılan bu oran kısıtları endüstriyel yumurta bütünü (ie) ve yumurta bütünü $(e)$ için farklılaşmaktadır. Yumurta sarısı ve yumurta akı ürünleri yalnızca 


\section{Murat Kocamaz ve Ural Gökay Çiçekli}

makine 2 tarafından üretilebildiği için buna benzer bir kısıt oluşmamaktadır.

Tablo 4: Makine 1 Girdisi Oranı

\begin{tabular}{lll} 
Ürünler & $\boldsymbol{M} \mathbf{1}_{\min }$ & $\boldsymbol{M 1 _ { \operatorname { m a x } }}$ \\
\hline Endüstriyel Yumurta Bütünü & $M 1_{\text {minie }}$ & $M 1_{\text {maxie }}$ \\
\hline Yumurta Bütünü & $M 1_{\min e}$ & $M 1_{\max e}$ \\
\hline
\end{tabular}

Sıvı oranı kısıtı. Ürünlerin içinde yer alan sıvı oranlarının $(L q)$ briks değerleri üzerinde yaratacakları etki göz önüne alındığında yumurta bütünleri için alt $\left(L q_{\min }\right)$ ve üst $\left(L q_{\max }\right)$ sınırının tanımlanması gerekmektedir. Yumurta sarısı ve yumurta akı ürünlerinde ise SIVI kullanımı olmamaktadır.

\section{Tablo 5: Sivı Oranı}

\begin{tabular}{lll} 
Ürünler & $L q_{\min }$ & $L q_{\max }$ \\
\hline Endüstriyel Yumurta Bütünü & $L q_{\min i e}$ & $L q_{\max i e}$ \\
\hline Yumurta Bütünü & $L q_{\min e}$ & $L q_{\max e}$ \\
\hline
\end{tabular}

Üretim miktarı kısıtı. Planlama dönemi içinde, kesinleşmiş ürün taleplerinin karşılanması modelin bir diğer kısıtını oluşturmaktadır. Planlama döneminde ürünlere ait istenilen alt $\left(P_{\min }\right)$ ve üst $\left(P_{\max }\right)$ değerler $\mathrm{kg}$ cinsinden girilebilmekte, sonrasında ise genel üretim hedefi tanımlanmaktadır. Bu genel üretim hedefleri toplam üretim miktarını maksimize etmek olabileceği gibi, kalan kapasiteyle yalnızca bir ürünü maksimize etmek de olabilir.

Tablo 6: Üretim Miktarı (Kg)

\begin{tabular}{lll} 
Ürünler & $\boldsymbol{P}_{\min }$ & $\boldsymbol{P}_{\max }$ \\
\hline Endüstriyel Yumurta Bütünü & $P_{\text {minie }}$ & $P_{\text {maxie }}$ \\
\hline Yumurta Bütünü & $P_{\text {mine }}$ & $P_{\text {maxe }}$ \\
\hline Yumurta SarıSı & $P_{\text {mingy }}$ & $P_{\text {maxey }}$ \\
\hline Yumurta Akı & $P_{\text {mingen }}$ & $P_{\text {maxew }}$ \\
\hline
\end{tabular}

\section{Değişkenler}

Model kapsamında girdileri oluşturan birçok değişken yer almaktadır. Bu değişkenler makine 1 ve makine 2'den gelen yumurta bütünü, akı, sarısı ve melanjı yanında aynı zamanda bunların hangi makineden geldiğini de ifade etmektedir. Ayrıca ürünlere girecek sIVI miktarları da değişken olarak tanımlanmaktadır. Bu kapsamda oluşturulan 


\section{Pastörize Likit Yumurta Üretim Planı Optimizasyonu}

değişken listesi ve bu değişkenlerin açıklamaları aşağıda kg cinsinden verilmektedir.

$x_{1}=$ "End. Yumurta Bütünü" için makine 1 den gelen bütün yumurta miktar

$x_{2}=$ "End. Yumurta Bütünü" için makine 2 den gelen bütün yumurta miktar

$x_{\mathrm{a}}=$ "End. Yumurta Bütünü" için makine 2 den gelen yumurta sarısı miktarı

$x_{4}=$ "End. Yumurta Bütünu" için makine 2 den gelen yumurta aku miktart

$x_{5}=$ "End.Yumurta Bütünü" için makine 2 den gelen melanj yumurta miktart

$x_{6}=$ "End.Yumurta Bütünü" için sivi miktarı

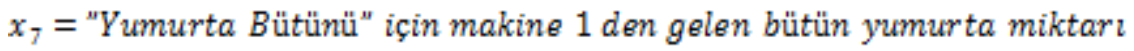

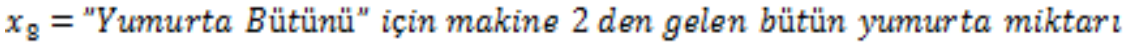

$x_{9}=$ "Yumurta Bütünü" için makine 2 den gelen yumurta sartsı miktart

$x_{10}=$ "Yumurta Bütünü" için makine 2 den gelen yumurta akt miktart

$x_{11}=$ "Yumurta Bütůnü" için makine 2 den gelen melanj yumurta miktart

$x_{12}=$ "Yumurta Bütünü" için swvi miktart

$x_{1 a}=$ "Yumurta Sarısı" için makine 2 den gelen bütün yumurta miktarı

$x_{14}=$ "Yumurta Sartst" için makine 2 den gelen yumurta sartst miktart

$x_{15}=$ "Yumurta Aku" için makine 2 den gelen yumurta aka miktart

\section{MODELİN KURULMASI}

Her bir ürünü oluşturan ürün reçeteleri değişkenler bazında aşağıda ifade edilmektedir. Üretim miktarları, o üründe kullanılan girdilerin $\mathrm{kg}$ toplamlarından hesaplanmaktadır.

"Endüstriyel Yumurta Bütünü" Toplam $K g=\sum_{i=1}^{n=6} x_{i}$

"Yumurta Bütünü" Toplam $K g=\sum_{i=7}^{n=12} x_{i}$

"Yumurta Sarisi" Toplam $K g=x_{19}+x_{14}$

"Yumurta Aku" Toplam $\mathrm{Kg}=x_{15}$

Üretim probleminin amaç fonksiyonu, mevcut kısıtlar altında, üretilebilecek maksimum çıktıyı sağlamaktır. Modellemede kullanılan amaç fonksiyonu aşağıda verilmektedir.

Modelde kullanılacak amaç fonksiyonu aşağıdaki denklemde verilmektedir.

Maks $Z=\sum_{i=1}^{n=15} x_{i}$

Modele ilişkin kısıt seti aşağıda sırasıyla verilmektedir.

$x_{1}+x_{7} \leq C d_{m i 1}$

$\sum_{i=2}^{n=5} x_{i}+\sum_{i=1}^{n=11} x_{i}+\sum_{i=12}^{n=15} x_{i} \leq C d_{m 2}$ 


\section{Murat Kocamaz ve Ural Gökay Çiçekli}

Makinelere ait kapasite kısıtları 7 ve 8 numaralı denklemlerde verilmektedir. Buna göre 7 numaralı denklemde makine 1'den gelen bütün yumurta kısıtı, 8 numaralı denklemde ise kalan diğer değişkenlere ait kısıtlar toplam $\mathrm{kg}$ cinsinden sağlanmaktadır.

$$
\begin{aligned}
& x_{a}+x_{9}+x_{14}=R_{E y} *\left(x_{a}+x_{4}+x_{5}+x_{9}+x_{10}+x_{11}+x_{14}+x_{15}\right) \\
& x_{4}+x_{10}+x_{15}=R_{E V} *\left(x_{a}+x_{4}+x_{5}+x_{9}+x_{10}+x_{11}+x_{14}+x_{15}\right) \\
& x_{5}+x_{11}=R_{E m} *\left(x_{a}+x_{4}+x_{5}+x_{9}+x_{10}+x_{11}+x_{14}+x_{15}\right)
\end{aligned}
$$

9, 10 ve 11 numaralı denklemler yumurta kırımı sonrası ortaya çıkan yumurta sarısı, yumurta akı ve yumurta melanjı miktarlarını ifade etmektedir. Bu kısıtlara göre ürünler içine girebilecek yarı mamuller $\mathrm{kg}$ cinsinden tanımlanmaktadır. Makine 2 'de işlenen bütün yumurtadan elde edilen yumurta sarısı oranı $R_{e y}$ yumurta akı oranı $R_{e w}$ ve yumurta melanjı oranı $R_{e m}$ çarpım olarak denklemlerde yer almaktadır.

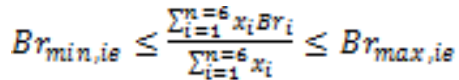

$$
\begin{aligned}
& B r_{\min _{\ell} \varepsilon} \leq \frac{\sum_{i=1}^{n=1 x_{1} B r_{i}}}{\sum_{i=1}^{n=12} x_{1}} \leq B r_{\max _{i} \varepsilon}
\end{aligned}
$$

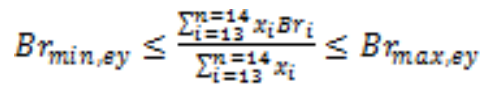

Ürünlerde sağlanması gereken briks değerlerinin alt ve üst kısıtları 12,13 ve 14 numaralı denklemlerde verilmektedir. 12 numaralı denklemde endüstriyel yumurta bütününün, 13 numaralı denklemde yumurta bütününün ve 14 numaralı denklemde yumurta sarısının istenilen briks değerlerinin alt ve üst kısıtları verilmektedir. Yumurta akı ürününde karışıma izin verilmediği için briks kısıtı yer almamaktadır.

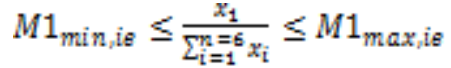

$$
\begin{aligned}
& M 1_{\min , \theta} \leq \frac{x_{7}}{\sum_{\mathrm{i}=7}^{n=12 x_{1}}} \leq M 1_{\max _{\ell} \theta}
\end{aligned}
$$

15 ve 16 numaralı denklemlerde, endüstriyel yumurta bütünü ve yumurta bütünü ürünlerinde makine 1 'den gelecek yumurta kg oranlarına ait alt ve üst kısıtlar belirlenmektedir.

$$
\begin{aligned}
& L q_{\text {minie }} \leq \frac{x_{6}}{\sum_{i=1}^{n=6 x_{1}}} \leq L q_{\max i \theta} \\
& L q_{\min , \theta} \leq \frac{x_{12}}{\sum_{i=7}^{n=1 x_{1}}} \leq L q_{\max , \theta}
\end{aligned}
$$

Endüstriyel yumurta bütünü ve yumurta bütünü ürünlerinde kullanılan sıvı miktarı oranına ilişkin kısıtlar sırasıyla 17 ve 18 numaralı denklemlerde verilmektedir. 


\section{Pastörize Likit Yumurta Üretim Planı Optimizasyonu}

$$
\begin{aligned}
& P_{\min , i \theta} \leq \sum_{i=1}^{n=6} x_{i} \leq P_{\max } \\
& P_{\min , \theta} \leq \sum_{i=7}^{n=12} x_{i} \leq P_{\max , \theta}
\end{aligned}
$$

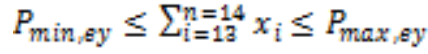

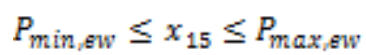

Endüstriyel yumurta bütünü, yumurta bütünü, yumurta sarısı ve yumurta akı ürünleri için istenilen üretim miktarlarının $\mathrm{kg}$ cinsinden alt ve üst sınırları sırasıyla 19, 20, 21 ve 22 numaralı denklemlerde verilmektedir.

\section{ÖRNEK UYGULAMA}

Çalışma kapsamında, likit yumurta üretimi yapan bir işletmenin üretim planlama problemi modellenmiş ve çözümünde GRG2 yönteminden faydalanılmışıı. Geliştirilen model, farklı kısıtların ve amaçların bulunduğu 54 farklı senaryo oluşturularak test edilmiştir. Firmanın rekabet ve gizlilik politikası nedeniyle bu bölümde çözüm aranan senaryolardan sadece bir tanesine yer verilmektedir.

\section{Modelin Optimizasyon Ayarları}

Modelin çözümü için Microsoft Office Excel çözücü ve makro eklentileri kullanılmışıır. Excel çözücü, düzgün doğrusal olmayan problem yapıları için Lasdon ve Smith (1992) ve Lasdon, Waren, Jain ve Ratner'in (1978) GRG2 kodunu kullanmaktadır.

Problemin çözümünde kısıtlama duyarlılığı 0,00001 ve yakınsama oranı 0,001 kullanılmışır. Çözüm metodu başlangıç için popülasyon boyutu 20 olmak üzere çoklu başlangıç opsiyonundan faydalanılmışıır. Çözümde Newton arama yönteminin ileri türevlerinden faydalanılmaktadır.

Makine kapasite kısıtları

$$
\begin{aligned}
& H_{m 1}=9(\text { saat }) E_{m 1}=0,85 C h_{m 1}=2500(\mathrm{~kg}) \\
& C d_{m 1}=H_{m 1} * E_{m 1} * C h_{m 1}=19125(\mathrm{~kg}) \\
& H_{m 2}=9(\text { saat }) E_{m 2}=0,85 C h_{m 2}=2750(\mathrm{~kg}) \\
& C d_{m 2}=H_{m 2} * E_{m 2} * C h_{m 2}=21038(\mathrm{~kg}) \\
& \text { Yumurta kırım oranları } \\
& R_{g y}=0,25 \\
& R_{g w}=0,32 \\
& R_{m m}=0,43
\end{aligned}
$$




\section{Murat Kocamaz ve Ural Gökay Çiçekli}

Briks kısıtları

$$
\begin{aligned}
& B r_{1}, B r_{2}, B r_{7}, B r_{9}, B r_{13}=26(b r) \\
& B r_{1}, B r_{g}, B r_{14}=43(b r) \\
& B r_{4}, B r_{10}, B r_{15}=14(b r) \\
& B r_{5}, B r_{11}=20(b r) \\
& B r_{6}, B r_{12}=0(b r) \\
& B r_{\text {min }_{\text {is }}}=21,50(\mathrm{br}) B r_{\text {maxis }}=22,50(\mathrm{br}) \\
& B r_{\min _{n} \theta}=23,50(b r) B r_{\text {max } \theta}=24,50(b r) \\
& B r_{\text {min }_{\triangleleft} \varepsilon y}=37,50(\mathrm{br}) B r_{\text {max }_{\triangleleft}, y}=38,50(\mathrm{br})
\end{aligned}
$$

Makine 1 girdisi kısıtları

$$
\begin{aligned}
& M 1_{\text {minis }}=0,40 \quad M 1_{\text {maxie }}=1,00 \\
& M 1_{\text {min }, Q}=0,00 \quad M 1_{\max , \varepsilon}=0,30
\end{aligned}
$$

Sıvı oranı kısıtları

$$
\begin{aligned}
& L q_{\min \text { is }}=0,00 \quad L q_{\max i s}=0,09 \\
& L q_{\min \theta}=0,00 L q_{\max \theta}=0,09 \\
& P_{\min , i \theta}=0(\mathrm{~kg}) \quad P_{\max _{i} \text { is }}=80000(\mathrm{~kg}) \\
& P_{\min _{g}}=10000(\mathrm{~kg}) P_{\max _{\ell}}=10000(\mathrm{~kg}) \\
& P_{\min , \varepsilon y}=4000(\mathrm{~kg}) P_{\max , \varepsilon y}=4000(\mathrm{~kg}) \\
& P_{\min _{, g N}}=0(\mathrm{~kg}) P_{\max _{\text {gnV }}}=500(\mathrm{~kg})
\end{aligned}
$$

\section{Tablo 7: Sonuç Çıktı Değerleri}

\begin{tabular}{lcc} 
Ürünler & Briks Değeri & Üretim Miktarı \\
\hline Endüstriyel Yumurta Bütünü & 21,5 & 29322 \\
\hline Yumurta Bütünü & 23,5 & 10000 \\
\hline Yumurta Sarısı & 37,5 & 4000 \\
\hline Yumurta Akı & 14,0 & 379
\end{tabular}

Makine yumurta kırım kapasiteleri \%100 kullanılmış, ihtiyaç fazlası ortaya çıkmamıştır.

\section{SONUÇ}

Tek bir girdiye sahip olan pastörize likit yumurta üretimi, 4 farklı ürün çıktısıyla, üretim planlama açısından birçok kısıt ve oransal ilişki tanımlanmasını zorunlu kılmaktadır. Bu oran ve kısıtlar çerçevesinde, firma tarafından yapılan üretim planı çözümlerinin modelin bulduğu 


\section{Pastörize Likit Yumurta Üretim Planı Optimizasyonu}

çözümlerden kötü sonuçlar verdiği görülmektedir. Çalışma kapsamında, bir işletmenin üretim planlama probleminin çözümünde faydalanılmak üzere GRG2 kullanılan model başarılı sonuçlar vermiştir. Geliştirilen model, 54 denemenin tümünde geçerli bir üretim programı oluşturmayı başarmıştır. Tüm senaryolarda belirlenen farkı kısıtlar karşılanarak istenilen amaçlara ulaşılmıştır. Üretim programlarından elde edilen fayda modelin performansı ile doğrudan ilişkilidir. Bu nedenle önerilen model ile oluşturulan üretim programı, müşteri isteklerinin başarı ile karşılanmasını sağlamaktadır.

\section{KAYNAKÇA}

Bazaraa, M.S., Sherali, H.D. ve Shetty, C.M. (2006). Nonlinear Programming: Theory and Algorithms. Hoboken, NJ: John Wiley \& Sons.

Boone, L.E. ve Kurtz, D.L. (2010). Contemporary Business. Hoboken, NJ: John Wiley \& Sons.

Edgar, T.F. ve Himmelblau, D.M. (1989). Optimization of Chemical Process. New York: McGraw-Hill.

Fahim, S.R. ve Helmy, W. (2012). Optimal Study of Distributed Generation Impact on Electrical Distribution Networks Using GA and Generalized Reduced Gradient. International Conference on Engineering and Technology (ICET 2012), 10-11 Ekim 2012.

Faluyi, F. ve Arum, C. (2012). Design Optimization of Plate Girder Using Generalized Reduced Gradient and Constrained Artificial Bee Colony Algorithms. International Journal of Emerging Technology and Advanced Engineering, 2(7), 304-312.

Kao, C. (1998). Performance of Several Nonlinear Programming Software Packages on Microcomputers. Computers \& Operations Research, 25(10), 807-816.

Kimball, D. (1991). Citrus Processing: Quality Control and Technology. New York: Springer Science.

Lasdon, L.S. ve Smith, S. (1992). Solving Sparse Nonlinear Programs Using GRG. ORSA Journal on Computing, 4(1), 2-15.

Lasdon L.S., Waren A., Jain A. ve Ratner, M. (1978). Design and Testing of a Generalized Reduced Gradient Code for Nonlinear Programming. ACM Transactions on Mathematical Software, 4(1), 34-50. 


\section{Murat Kocamaz ve Ural Gökay Çiçekli}

Lee, H.T., Chen, S.H. ve Kang, H.Y. (2004). A Study of Generalized Reduced Gradient Method with Different Search Directions. Journal of Measurement Management, 1(1), 25-38.

Mouatasim, A.E. (2010). Two-Phase Generalized Reduced Gradient Method for Constrained Global Optimization. Journal of Applied Mathematics, Article ID: 976529.

Prochaska, J.F, Carey, J.B. ve Shafer, J. (1996). The Effect of L-lysine Intake on Egg Component Yield and Composition in Laying Hens. Poultry Science, 75(10), 1268-77.

Rardin, R.L. (1998). Optimization in Operations Research, New Jersey: Prentice Hall.

Sharma, R. ve Glemmestad, B. (2013). On Generalized Reduced Gradient Method with Multi-start and Self-optimizing Control Structure for Gas Lift Allocation Optimization. Journal of Process Control, 23, $1129-1140$.

Su, C.T. ve Lii, G.R. (1995). Reliability Optimization Design of Distribution Systems via Multi-level Hierarchical Procedures and Generalized Reduced Gradient Method, Energy Management and Power Delivery. Proceedings of EMPD '95 International Conference (21-23 Nov 1995), 180-185.

Sun, W. ve Yuan, Y. (2006). Optimization Theory and Methods: Nonlinear Programming. New York: Springer.

Ulucan, A. (2004). Yöneylem Araştırması: İşletmecilik Uygulamalı Bilgisayar Destekli Modelleme. Ankara: Siyasal Kitabevi.

Wolfe, P. (1963). Methods of Nonlinear Programming, Recent Advances in Mathematical Programming. New York: Mcgraw-Hill.

Yeniay, Ö. (2005). A Comparative Study on Optimization Methods for the Constrained Nonlinear Programming Problems. Mathematical Problems in Engineering, 2005(2), 165-173. 